\title{
Características e oportunidades da desregulação: a busca por um novo modelo de atuação estatal
}

Deregulation characteristics and opportunities: looking for a new model for state intervention

Gabriel Boavista Laender*

\section{Resumo}

O presente artigo tem por objetivo debater de que modo os atuais desafios quanto à eficácia da atuação do Estado sobre a economia resultaram em novos modos de atuação estatal. Para tanto, parte de uma análise conceitual do chamado processo de desregulação, ao que identifica um viés próprio da experiência europeia (chamado meta-regulation), e outro próprio à experiência estadunidense (chamado adversarial legalism). Em seguida, são associadas algumas características típicas das agências reguladoras a essas duas experiências de desregulação, de modo a se firmarem pontos de identificação. Por fim, conclui-se que essas características abrem espaço para novos mecanismos de atuação estatal para objetivos outros que não apenas o desenvolvimento econômico.

\section{Abstract}

This article debates whether current challenges facing the effectiveness of state regulation resulted in new ways of state interaction with the economy. For that purpose, the article begins with a conceptual analysis of the so-called deregulation, addressing the European experience (meta-regulation) and the American one (adversarial legalism). Next, some of the typical characteristics of the regulatory agencies are associated with those two experiences of deregulation, in order to find out similarities. The article then concludes that those characteristics add new objectives other than the economic development for state regulation.

\section{Introdução: a busca de um novo Estado}

A discussão em torno de agências reguladoras ganhou força a partir dos debates em torno da reforma do Estado, ocorridos especialmente a partir da

*Mestre em Direito, Estado e Constituição pela Universidade de Brasília (UnB); Especialista em Regulação de Telecomunicações pela UnB; Pesquisador do Grupo de Estudos em Direito das Telecomunicações da UnB. Procurador do Estado do Espírito Santo. Assessor da Secretaria de Assuntos Estratégicos da Presidência da República. 
década de 90 do século passado - com a importante precedência das experiências da Inglaterra de Margareth Thatcher, do Chile de Pinochet e dos Estados Unidos de Ronald Reagan, na década de 80. A partir da difusão da noção de que o Estado não havia mais como sustentar os gastos do Estado do Bem-Estar Social, propagou-se a necessidade de reestruturação do aparato estatal e redução do tamanho do Estado. ${ }^{1}$ Seguiu-se uma agenda internacional de promoção da desestatização e da privatização de setores específicos da atividade econômica, então objeto da atuação direta do Estado mediante sociedades empresárias sob controle estatal e submetidas a regimes de garantia jurídica de monopólio - no caso dos EUA, regime de monopólio combinado a obrigações de interesse público incidentes sobre as empresas monopolistas, que todavia não pertenciam ao Estado. ${ }^{2}$ Substituiuse o discurso de crescimento econômico por meio da ação estatal (State-led growth) pelo discurso de crescimento econômico por meio da ação das forças naturais de mercado (market-led growth). Ganhou força na agenda política a doutrina que declarava que a atuação estatal deveria a ser a de promoção da competição, como condição para o desenvolvimento. ${ }^{3}$

Todavia, se em um primeiro momento houve uma identificação clara dessa agenda com a dita ideologia neoliberal, em especial em decorrência da iminente necessidade de ajuste fiscal enfrentada por diversos países, não há contudo como fazer a exata correspondência entre neoliberalismo e reforma do Estado. ${ }^{4}$ A adoção de políticas de retração do Estado em países como Chile, EUA e Inglaterra acabou trazendo resultados inicialmente frustrantes em termos de crescimento econômico. Países que expressamente declararam a adoção de medidas neoliberais tiveram pálidos resultados econômicos nos anos $80 .^{5}$ Assim, enquanto na década de 80 propagou-se a adoção do

${ }^{1}$ Sobre a crise fiscal e a demanda por um estado mais eficiente, cf. PEREIRA, 1998, p. 22-23; ARIÑO ORTIZ, 2004, p. 600-601; JUSTEN FILHO, 2002, p. 18-19; sobre as implicações da crise e o avanço da ideologia neoliberal, cf. ANDERSON, 2000, p. 10-15.

${ }^{2}$ Sobre o monopólio nos EUA no setor de telecomunicações, cf. HUBER, KELLOG e THORNE, 1999, p. 1-78.

${ }^{3}$ Entre os doutrinadores que pregam a competição como o objetivo da intervenção regulatória, destacam-se, no plano internacional, Scott Jacobs, Gaspar Ariño Ortiz e Anthony Ogus (Cf. MORGAN e YEUNG, 2007, p. 16 e ss.).

${ }^{4}$ Cf. PEREIRA, 1998 , p. 30-33.

${ }^{5}$ Cf. GIDDENS, 2007, p.17-19; ANDERSON, 2000, p. 15-23.

Revista de Direito, Estado e Telecomunicações, v. 1, n. 1, p. 181-202 (2009)

DOI: https://doi.org/10.26512/lstr.v1i1.21743 
chamado Estado mínimo, na década de 90 foi paulatinamente reconhecida a necessidade de um Estado regulador $^{6}$, cuja atuação foi considerada necessária para que os mercados funcionassem adequadamente e, assim, houvesse aumento no bem-estar social. ${ }^{7}$ Importante, porém, ressaltar que essa postura é ainda permeada pela noção de que o livre mercado seria a forma naturalmente mais eficiente de promoção do bem-estar - o reconhecimento da necessidade da atuação estatal ocorre na medida em que essa é instrumento para que se eliminem falhas de mercado.Essas falhas incluiriam, por exemplo, monopólios naturais, externalidades, assimetrias de informação entre firmas e consumidores etc. Em última análise, a intervenção estatal seria justificada para emular as condições de funcionamento de um mercado perfeito. ${ }^{8}$

Assim, ao mesmo tempo em que se reconhecem mais funções ao Estado - e, em decorrência, a necessidade de ampliação do correspondente aparato estatal -, essas funções são identificadas com o mercado. A capacidade do Estado de dialogar com o mercado passou a ser medida de sua eficácia. E uma vez que toda a discussão está inserida na busca de mecanismos de desenvolvimento econômico, o discurso de legitimidade da atuação estatal passou a ser o da eficácia do Estado na promoção desse desenvolvimento econômico e, logo, da sua capacidade de bem dialogar com o mercado. Em decorrência, passou-se a exigir que o aparato estatal tenha competência técnica para aferir o mercado, identificar suas necessidades e tomar as providências necessárias para que se emulem com a maior aproximação possível as condições da livre concorrência.

Aliada à competência técnica, essa linha política e doutrinária prega a agilidade e eficiência do Estado, para acompanhar o dinamismo do mercado já entendido como instituição global, e não mais nacional. Frente a um mercado global, a ausência de eficiência e agilidade resultaria na perda de

${ }^{6} \mathrm{Cf}$. JUSTEN FILHO, 2002, p. 20-25.

7"As transformações ocorridas nos últimos anos (de forma acentuada no Brasil, mas igualmente em vários países do continente europeu que guardam muita semelhança com nossa tradição de intervenção estatal e de estrutura jurídica) apontam para uma redução da intervenção direta e do incremento de uma nova forma de intervenção, substancialmente distinta daquela acima divisada. Tem lugar entre nós o fortalecimento do papel regulador do Estado em detrimento do papel do Estado produtor de bens e serviços.” (MARQUES NETO, 2005, p. 29.)

${ }^{8}$ Cf. ARIÑO ORTIZ, 2004, p. 603 e ss.

Revista de Direito, Estado e Telecomunicações, v. 1, n. 1, p. 181-202 (2009) 
investimentos e no deslocamento da produção para países vizinhos. Enquanto no surgimento do Estado Moderno o poder político - monopólio sobre o uso legítimo da força - era o fundamento de sua soberania e de sua capacidade de desenvolvimento, no Estado Contemporâneo o poder político cede espaço ao poder econômico. ${ }^{9}$ Com a globalização dos mercados, o poder econômico - que nunca foi objeto do monopólio de legitimidade estatal - passa a ser desvinculado dos estados nacionais. A livre movimentação financeira global desnacionalizou o capital. E este, em um mundo globalizado, passou a ser barganhado em um mercado em que o próprio Estado integra o lado da demanda. Há nesse ponto uma mercantilização da própria atuação estatal, pois de um lado o Estado vira consumidor de agentes de produção e investimento estrangeiro, e de outro lado o provedor de regras e condições demandadas por esses agentes. A própria regulação - junto com outros fatores como estabilidade econômica, presença de mão-de-obra qualificada, infra-estrutura de serviços avançados etc. - passa a integrar o preço pago pelo Estado para comprar poder econômico. ${ }^{10}$ A regulação, por esses pressupostos, passa a ser medida pelo grau de confiança depositado no Estado pelo mercado. Quanto mais a

${ }^{9}$ Todavia, a perda de eficácia do poder político não ocorre apenas frente ao poder econômico. Manuel Castells, a esse respeito, é esclarecedor: “(...) além da complexa relação com as mais variadas formas de expressão de poder/representação política, o Estado-Nação vem sendo cada vez mais submetido a uma concorrência mais sutil e problemática de fontes de poder indefinidas e, às vezes, indefiníveis. Trata-se de redes de capital, produção, comunicação, crime, instituições internacionais, aparatos militares supranacionais, organizações não-governamentais, religiões transnacionais e movimentos de opinião pública. Em um nível abaixo do Estado, há as comunidades, tribos, localidades, cultos e gangues. Assim, embora os Estados-Nação realmente continuem a existir, dentro de um futuro previsível, eles são, e cada vez mais serão, nós de uma rede de poder mais abrangente." (CASTELLS, 2006, p. 353) ${ }^{10}$ Não se faz aqui adesão à Teoria Econômica da Regulação (STIGLER, 2004), segundo a qual a regulação é produto de uma relação entre oferta e demanda em que, do lado da oferta, estão os agentes regulados e, do outro lado, está o Estado. A afirmação ora feita tem caráter metafórico apenas, e busca evidenciar que a presença de valores democráticos na atuação estatal, ou a proteção valorativa a direitos, não é sequer ponderada nesse jogo de poder no que diz respeito à legitimação pelos agentes econômicos da condução das políticas públicas de intervenção econômica. Além disso, ao contrário do que diz a Teoria Econômica da Regulação, entende-se que essa situação de mercantilização da regulação é contingencial - não estrutural e, portanto, passível de alteração mediante ação política consciente.

Revista de Direito, Estado e Telecomunicações, v. 1, n. 1, p. 181-202 (2009)

DOI: https://doi.org/10.26512/1str.vli1.21743 
regulação for identificada com o mercado, maior a confiança dos agentes. Quanto maior a confiança depositada pelo mercado, maior a capacidade de atração de capital. Quanto mais capital se atrair, maior será o desenvolvimento econômico.

Nesse contexto, na medida em que procura resolver o problema de financiamento do Estado e em que adota o desenvolvimento econômico como parâmetro de legitimidade, o movimento de reforma do Estado passa a ter por objetivo a adoção de mecanismos institucionais que: i) diminuam os custos de operação do Estado; ii) dotem o Estado de mecanismos de agilidade e competência técnica necessários à resposta de confiança demandada pelos agentes econômicos; iii) privilegiem a obtenção de resultados, em detrimento do controle dos meios utilizados. Foi sob essas premissas que o modelo de agências reguladoras proliferou como paradigma institucional contemporâneo.

O contexto histórico acima descrito, porém, não deve ser determinante para a análise do modelo, especialmente por se ter em conta que seu surgimento nos EUA precede a discussão de reforma do Estado dos anos 80 e 90. Todavia, essa discussão evidencia alguns elementos-chaves aptos a esclarecer a busca pela configuração institucional do Estado em países como o Brasil, que acaba por demandar organizações com as características próprias das agências reguladoras. Sendo assim, nesses países, o modelo institucional de agências reguladoras pode ser identificado com a busca de políticas públicas cujo meio de promoção de desenvolvimento econômico seja determinado pelo discurso técnico e pelo provimento de confiança a mercados como forma de obtenção de poder econômico. A percepção desses aspectos permite, mediante maior análise, a comparação com outros modelos como o de autarquias ou fundações públicas, que, em função de seu contexto histórico e das necessidades que pautaram sua adoção, podem ter eventuais matizes diferentes de características similares ao modelo de agências reguladoras. 


\section{Ferramentas de sobrevivência do Estado: modos de desregulação ${ }^{11}$}

Como dito acima, o discurso político e doutrinário atribuiu ao Estado Nacional, atingido pela crise fiscal dos anos 80, um novo papel. No movimento de busca por eficiência e agilidade, a primeira alternativa foi a adoção da cartilha neoliberal ${ }^{12}$ de redução do tamanho do Estado. Em seguida, reconheceu-se a necessidade de um Estado maior, porém calcado em mecanismos de intervenção indireta do Estado na economia e que tivesse por objetivo principal a busca pela competição como meio de promoção do desenvolvimento econômico.

A reforma do Estado correspondeu à ruptura com o modelo burocrático de administração pública. Apesar da conotação negativa que hoje carrega, a burocracia foi uma evolução inegável no que diz respeito ao tratamento da coisa pública (res publica) e no estabelecimento de um corpo estatal de profissionais. O objetivo da gestão burocrática era impedir o patrimonialismo (a incapacidade ou a relutância de o príncipe distinguir entre o patrimônio público e seus bens privados ${ }^{13}$ ). Sua função primordial era evitar o nepotismo e a corrupção, mediante o controle hierárquico e formalista dos procedimentos. A posterior redução do Estado, por sua vez, significou a redução da burocracia e o aumento de espaços de atuação privada. Questões antes decididas no espaço estatal passaram a ser legadas à iniciativa privada. Essa experiência teve como expoentes o Governo Reagan nos EUA, o Governo de Thatcher na Inglaterra e o Governo de Pinochet no Chile.

Todavia, a opção que acabou por ser mais difundida não foi uma mera redução do aparato do Estado, mas a mudança na postura estatal, buscando o desenvolvimento pelo mercado. A mudança institucional correspondente ao escopo de liberalização do mercado foi genericamente denominada pela doutrina como deregulation ou, em uma tradução livre, desregulação. ${ }^{14} \mathrm{E}$

${ }^{11}$ A expressão pertence a Giampiero Di Plínio: toolkit di sopravvivenza (2005, p. 23). ${ }^{12}$ Segundo Giddens, uma mistura de liberalismo de mercado e autoritarismo moral (2007, p. 18).

${ }^{13}$ PEREIRA, 1998, p. 26.

${ }^{14}$ O Black's Law Dictionary define deregulation como the reduction or elimination of governmental control of business, esp. to permit free markets and competition Revista de Direito, Estado e Telecomunicações, v. 1, n. 1, p. 181-202 (2009) 
importante frisar que o que se chama de deregulation, porém, não tem um significado comum na doutrina ou na experiência política. Sob essa alcunha, políticas públicas as mais diversas foram executadas, e não são poucos os que afirmam que a desregulação não significou menos regulação, mas sim a adoção de outros mecanismos de atuação estatal diversos, que agregam elementos não-coercitivos (cooperativos, portanto) aos instrumentos à disposição do Estado. ${ }^{15}$

$\mathrm{Na}$ Europa, em especial, a deregulation não significou a retirada do Estado de setores da economia, ao menos não em um primeiro momento, mas sim a adoção de práticas estatais voltadas à liberalização de mercados e à substituição da função do Executivo de promotor do desenvolvimento econômico a indutor da concorrência. Como ponto comum entre a experiência americana e a europeia está o escopo de liberalização do mercado, porém na Europa a liberalização significou a retirada de monopólios estatais e a implementação da livre competição - o que significou a retirada de mecanismos de intervenção operacional do Estado. É ainda possível identificar uma agenda europeia de retirada de mecanismos estatais de intervenção normativa, na medida em que os mercados se tornem mais competitivos. Não obstante, é ainda cedo para se averiguar se essa agenda permanecerá, uma vez que mesmo doutrinadores europeus de forte viés liberalizante - como Ariño Ortiz - entendem que há determinados setores em que a presença específica do Estado é fundamental para a garantia da própria concorrência.

A experiência da deregulation, conforme Giampiero Di Plínio, ocorre por dois vieses de experiência de regulação, ambos opostos ao modelo burocrático: o adversarial legalism e a meta-regulation. $\mathrm{O}$ adversarial legalism é, em verdade, característico do direito americano e significa a adoção de um conjunto de estruturas e de uma prática jurídica ${ }^{16}$ que transferem às partes envolvidas a condução do processo, a produção de argumentos e de provas, e deixa a cargo de uma autoridade independente a discricionariedade para, informada pelas partes, tomar determinada decisão.

(verbete deregulation, p. 475). Sobre a deregulation americana e seu impacto na Teoria Econômica da Regulação, vide PELTZMAN, 2004.

${ }^{15} \mathrm{Cf}$. AYRES e BRAITHWAITE, 1992; HANCHER e MORAN, 1989.

${ }^{16}$ Nos termos de Kagan (2007, p. 104), a set of legal structures and a legal practise. 
O adversarial legalism é a configuração que tomou no direito americano o adversary system ${ }^{17}$, de origem britânica. Logo, não se refere propriamente a uma forma de regulação, mas a toda uma tradição jurídica que se baseia no acesso individual ao Judiciário como forma de proteção de direitos. ${ }^{18}$ Por um lado, a implementação de políticas públicas por meio de mecanismos baseados no acesso das partes prejudicadas ao Judiciário, e, por outro lado, a reprodução de práticas judiciais pela Administração Pública, combinada com a adoção de estruturas administrativas com características semelhantes a juízos, é o que se chama adversarial legalism como modo de regulação. Di Plínio, por esse motivo, vê a adoção do adversarial legalism como uma judicialização da política $^{19}$ Robert Kagan, a respeito da adoção do adversarial legalism, traz exposição esclarecedora do porquê desse modo de regulação:

(...) nos últimos 40 anos, pressões políticas por um governo mais ativo intensificaram 0 adversarial legalism americano (...). A partir dos anos 60, movimentos políticos e grupos de sociedade civil organizada demandaram proteções governamentais cada vez mais intensas contra discriminação racial, desigualdade de sexos, crimes violentos, degradação ambiental, produtos e tecnologias de risco, desamparo econômico súbito, tratamento arbitrário pela polícia e por burocracias governamentais, entre outros. A resposta a essas demandas políticas requereu um governo central mais poderoso, mais ativista - o que conflitava com uma tradição política de governo descentralizado e

${ }^{17} \mathrm{O}$ adversary system é chamado pela doutrina brasileira de sistema acusatório e tem origem no processo criminal. Opõe-se ao sistema inquisitorial dos países continentais - adotado pelo Brasil -, em que a condução do processo fica a cargo da autoridade pública e as partes têm função auxiliar.

${ }^{18}$ Sobre o adversarial legalism, Robert Kagan esclarece: "To encapsulate some of these distinctive qualities of governance and legal process in the USA, I use the shorthand term "adversarial legalism" - a mode of policy-making, policy implementation, and dispute resolution that encourages lawyer-dominated litigation. Organizationally, adversarial legalism is associated with decision-making institutions in which authority is fragmented and in which hierarchical control is relatively weak. At the level of litigation and adjudication, a key feature of adversarial legalism is litigant activism: the assertion of claims, the search for controlling legal arguments, and the gathering and submission of evidence is dominated not by judges or governmental officials, but by disputing parties or interests, acting primarily through lawyers." (KAGAN, 2007, p.103).

${ }^{19}$ DI PLINIO, 2005, p. 34.

Revista de Direito, Estado e Telecomunicações, v. 1, n. 1, p. 181-202 (2009)

DOI: https://doi.org/10.26512/lstr.vli1.21743 
limitado. 0 adversarial legalism proveu uma forma de reconciliar, mesmo que brutamente, esses contraditórios desejos políticos. Grupos da sociedade civil organizada que buscavam novos direitos se voltaram às cortes, e juízes americanos politicamente engajados frequentemente extraíam esses direitos da common law, de leis ou de normas constitucionais. Políticos promulgaram leis que garantiam aos administradores mais poder (inclusive pesadas sanções legais), mas, temendo que os entes da Administração - federais, estaduais e locais atuassem com parcialidade política, eles constrangeram a discricionariedade das agências por meio de regras detalhadas e requisitos procedimentais, conferindo legitimidade ativa tanto a entes regulados como a organizações não-governamentais (ONGs) para contestar judicialmente as decisões administrativas (...). Em suma, juízes americanos e políticos adotaram ações judiciais, processos formais, direitos, duras penalidades legais, advogados e cortes - as pedras fundamentais do adversarial legalism - ao invés das poderosas burocracias, dos entes corporativistas, dos bancos centrais e dos programas de seguridade social que dominaram o Estado Regulatório de Bem-Estar Social na Europa Ocidental. ${ }^{20}$

20 "...in the last 40 years, political pressures for more active government have intensified American adversarial legalism [...]. Beginning in the 1960s, political movements and advocacy groups demanded increasingly comprehensive governmental protections from racial discrimination, gender inequality, violent crime, environmental degradation, hazardous products and technologies, sudden economic loss, arbitrary treatment by police and governmental bureaucracies, and so on. Responding to these political demands required a more powerful, more activist central government - which conflicted with a political tradition of limited, decentralized government. Adversarial legalism provided a way of reconciling, however roughly, these inconsistent political desires. Advocacy groups seeking new rights turned to the courts, and politically responsive American judges often read those rights into the common law, statutes, and constitutional provisions. Politicians enacted statutes that granted administrators more power (including tough legal sanctions), but fearing political bias by agencies - federal, state, and local - they constrained agencies' discretion with detailed rules and procedural requirements, empowering both regulated entities and non-governmental organizations (NGOs) to challenge administrators' decisions in court [...]. In sum, American judges and politicians have substituted lawsuits, formal procedures, rights, tough legal penalties, lawyers, and courts - the building blocks of adversarial legalism - for the powerful bureaucracies, corporatist bodies, central banks, and social insurance programs that have dominated the regulatory-welfare state in Western Europe." (KAGAN, 2007, p.105 - tradução livre).

Revista de Direito, Estado e Telecomunicações, v. 1, n. 1, p. 181-202 (2009) 
A meta-regulation, por sua vez, significa regular a regulação - ou seja, estabelecer regras que limitem e disciplinem a adoção de mecanismos de intervenção normativa e operacional estatais. A meta-regulation é base para o conceito de responsive regulation elaborado por Ian Ayres e John Braithwaite $^{21}$, e que tem tido muita influência na regulação europeia. A responsive regulation parte do princípio segundo o qual, na área regulatória, é melhor prevenir os conflitos do que resolvê-los a posteriori. Busca-se privilegiar a negociação e o consenso, com ênfase em métodos alternativos de resolução de conflitos - não-judiciais, portanto. Consideram-se os métodos alternativos mais eficientes, eficazes e econômicos. Mais ainda, considera-se o debate como o meio mais eficaz de obter justiça. A esse respeito, John Braithwaite esclarece:

A idéia nuclear da justiça reparadora [restorative justice] é que, porque a injustiça fere, a justiça deve curar. A cura, argumenta-se, é mais provável quando há deliberação sem dominação entre os interessados [stakeholders] acerca das consequiências da injustiça e do que deve ser feito para corrigir o mal. A idéia central da responsive regulation é que a regulação (seja por governos ou por outros atores que regulem) deve oferecer respostas rápidas e eficazes às posturas motivacionais dos regulados (...), aos seus costumes, sua real conduta e aos fatos estruturais dos mercados regulados. Como a justiça reparadora, a responsive regulation parte da alegação de que instituições deliberativas legalmente pluralistas que engajem múltiplos stakeholders têm maiores chances de assegurar os propósitos regulatórios dessas instituições. Como a justiça reparadora, a responsive regulation valoriza a flexibilidade e a participação dos cidadãos na manufatura de soluções contextualmente sintonizadas com problemas, e parcimônia no recurso à coerção. ${ }^{22}$

${ }^{21} \mathrm{Cf}$. AYRES e BRAITHWAITE, 1992.

${ }^{22 " A}$ core idea of restorative justice is that because injustice hurts, justice should heal. Healing, it contends, is most likely when there is undominated deliberation among stakeholders about the consequences of the injustice and what should be done to right the wrong. The core idea of responsive regulation is that regulation (whether by governments or other actors who regulate) should be responsive to the motivational postures of the regulated [...], to their customs, their actual conduct and to structural facts about regulated markets. Like restorative justice, responsive regulation makes the explanatory claim that legally pluralist deliberative institutions that engage multiple stakeholders are most likely to secure the regulatory purposes of such institutions. Like restorative justice, responsive regulation values flexibility, 
A meta-regulation consiste na reflexão sobre as próprias políticas regulatórias, com enfoque nas instituições e nos processos que compõem a estrutura administrativa, de modo a conferir racionalidade econômica à rotina diária de atuação política. ${ }^{23} \mathrm{O}$ uso do termo foi especificamente difundido para designar a aproximação entre regulação e auto-regulação, nomeando a atividade de organismos neutros e independentes que atuam sobre os reguladores ou auto-reguladores. Designou o monitoramento do auto-monitoramento das corporações. ${ }^{24}$ Assim, a normatização das atividades reguladas compete aos próprios agentes do setor regulado, e o ente regulador tem função de mediador e supervisor. ${ }^{25}$ Adota-se, portanto, uma visão de regulação como controle de atividades auto-reguladas. ${ }^{26}$

Nesse contexto, a adoção de estruturas administrativas com características judiciais (independência, neutralidade técnica, imparcialidade, desinteresse), porém que não integram a estrutura jurisdicional, configura a busca por uma legalidade não-judicial (nonjudicial legality), pautada na prevalência de um discurso de justificação técnico - e não político -, porém não identificado com o discurso jurídico tradicional. Em substituição a esse discurso jurídico, a meta-regulation em geral opta pelo discurso econômico, avaliando instituições e regras em termos de eficiência econômica, e aspectos distributivos em termos de falhas de mercado. Uma vez que se caracteriza como uma regulação sobre a regulação, a meta-regulation tem por fim a retirada de barreiras à competição - e à economia em geral - que não encontrem respaldo na racionalidade econômica. Assim, sua adoção significa um política de auto-

citizen participation in crafting contextually attuned solutions to problems and parsimony in recourse to coercion." (BRAITHWAITE, 2003, p. 7 - tradução livre).

23“"The notion of meta-regulation is simple at heart: it captures a desire to think reflexively about regulation, such that rather than regulating social and individual action directly, the process of regulation itself becomes regulated." (MORGAN, 2003, p. 2).

24“"The term [meta-regulation] has been used previously (Gunninngham and Grabosky, 1998; Parker, 2002) to capture developments at the intersection of state regulation and self-regulation, where government monitors the self-monitoring of corporations. "(MORGAN, 2003, p. 2).

${ }^{25}$ DI PLINIO, 2005, p. 40.

${ }^{26}$ DI PLINIO, 2005, p. 44.

Revista de Direito, Estado e Telecomunicações, v. 1, n. 1, p. 181-202 (2009) 
contenção do Estado, privilegiando os espaços privados de resolução de conflitos e de desenvolvimento econômico.

Desse modo, embora configurem dois vieses distintos de desregulação, o adversarial legalism e a meta-regulation não são necessariamente excludentes entre si. O adversarial legalism parte de uma óptica de reforço de direitos mediante o recurso a práticas identificadas com a experiência judicial norte-americana, pautada especialmente no direito de ação dos interessados e na função destes de instruir agentes públicos independentes, por meio de um processo detalhado e que garanta ao máximo a participação igualitária dos interessados na produção de provas e argumentos. Seu foco, portanto, é a relação entre o Estado e os administrados. A meta-regulation, por sua vez, parte de uma lógica de restrição da atividade estatal, segundo uma racionalidade que pode ser alternativa ao discurso político ou técnicojurídico, optando-se no mais das vezes pela técnica econômica. $\mathrm{O}$ foco desta última é a relação entre Estado e regulador - seja este regulador público ou privado (auto-regulação). A relação entre regulador e regulado, ao invés de ser seu objeto principal, é o meio em que incide a nova racionalidade adotada, de sorte a avaliar a própria regulação. Desta forma, a própria capacidade de os particulares buscarem a implementação de direitos por mecanismos judiciais integra essa racionalidade, de sorte que Braithwaite estabelece que a possibilidade de recurso a mecanismos coercitivos de solução de conflitos - como o Judiciário é capaz de prover - é um dos pressupostos de eficiência da meta-regulation..$^{27}$ Isso porque, sabendo os custos de um litígio, as partes tenderão racionalmente a cooperar, o que auxiliará a implementação da racionalidade subjacente à meta-regulation.

Tanto um caso (adversarial legalism), como o outro (meta-regulation), configuram respostas do Estado à perda de eficácia do poder político e à internacionalização do poder econômico. Essas perdas, somadas à crescente dimensão transnacional da Constituição Econômica - pautada cada vez mais em instrumentos supranacionais, e referente a uma realidade cada vez mais globalizada -, demandaram uma nova postura estatal, que acabou resultando em mecanismos de diminuição do tamanho do Estado e, principalmente, em novas formas de interação entre Estado e mercado. Essas novas formas de interação acabaram constituindo, na feliz expressão de Di Plínio,

${ }^{27}$ BRAITHWAITE, 2003, p. 6-7.

Revista de Direito, Estado e Telecomunicações, v. 1, n. 1, p. 181-202 (2009)

DOI: https://doi.org/10.26512/lstr.v1i1.21743 
ferramentas (toolkits) de sobrevivência do Estado frente a uma nova realidade jurídica e econômica. ${ }^{28}$

Contudo, esses toolkits trazem perplexidades mesmo com relação à interação entre Estado e mercado, pois, como afirma Jacobs:

(...) mudanças na relação entre Estado e mercado são muito mais profundas e intensas do que se pode explicar mediante a análise do mercado sozinho. Isto ajuda a explicar por que não há ainda nenhum conceito coerente do papel do Estado em um período de crescimento global liderado pelo mercado (market-led growth). A reforma estrutural é parte da corrente de evolução de governança e de relações entre Estados e mercados nas democracias capitalistas. As questões que mobilizam a reforma hoje não são inteiramente questões de eficiência, porém temas muito mais fundamentais acerca das cambiantes relações na sociedade. ${ }^{29}$

Não obstante, essas duas principais correntes que pautaram a experiência de desregulação trouxeram necessidades específicas nos entes da Administração Pública incumbidos de promover a regulação. Em especial, as características específicas associadas às agências reguladoras podem (e devem) ser relacionadas a cada uma dessas duas tendências.

\section{Os mecanismos de atuação das agências reguladoras frente à nova realidade estatal}

As instituições surgidas partir da experiência de reforma de Estado tiveram de agregar características próprias que lhes permitissem, de um

${ }^{28}$ Contudo, cabe enfatizar que o enfoque resultante da desregulação, se não criou 0 Estado Subsidiário neoliberal, acabou resultando em um estrangulamento das instituições governamentais. Fala-se em reformas de segunda geração, com o objetivo de mudar o papel do Estado e, assim, conferir sentido à atuação estatal no mundo moderno. Por isso mesmo, as reformas compõem um kit de sobrevivência estatal frente aos novos modos de interação da economia e às novas pretensões públicas de regulação pelo Estado.

29“"...) changes to the market-state relationship are much deeper and more profound than can be explained by examining the market alone. This helps explain why there is, as yet, no coherent concept of the role of the state in a period of global market-led growth. Structural reform is part of the ongoing evolution of governance and relations between states and markets in capitalist democracies. The issues driving reform today are not largely technical issues of efficiency, but far more fundamental issues about changing relations in society." (JACOBS, 1999, p. 9 - tradução livre). 
lado, corresponder às necessidades motoras da reforma (redução de custos, busca de eficiência, agilidade, entre outros) e, de outro, implementar os objetivos regulatórios resultantes da mudança das relações entre Estado e mercado.

Para avaliar as características das agências reguladoras, propõem-se três critérios: a) estrutural, que leva em conta a organização da estrutura e a inserção dos entes administrativos no aparato estatal; b) funcional, que leva em conta as funções atribuídas ao ente regulador; c) procedimental, que leva em conta condicionamentos processuais para o exercício das funções do ente regulador.

\section{Critério estrutural}

As agências reguladoras são estruturadas de modo a assegurar o máximo de independência na tomada de decisões. Nesse ponto, adversarial legalism e meta-regulation são convergentes. Exige-se, do lado do adversarial legalism, que, se a competência para dirimir conflitos seja atribuída à Administração Pública, ela seja exercida por ente com características de imparcialidade típicas de um juiz. É natural que as partes de um conflito recorram a um terceiro para que se encontre uma decisão imparcial, porém esta imparcialidade do terceiro deve ser garantida. Dada a natureza tripolar de um modelo judicializado de resolução de conflitos, a parcialidade do julgador resultaria na união de dois pólos contra um, o que acabaria por propiciar injustiça ainda maior do que a ausência do julgador. ${ }^{30}$ Assim, deve-se criar uma estrutura que seja protegida de parcialidades específicas, que seja capaz de dar um tratamento igualitário às partes. Essa estrutura combina-se com a necessidade de que as decisões produzidas respeitem um discurso de conformação a regras jurídicas pré-estabelecidas ao conflito, e que a racionalidade da decisão seja aplicável a todos os casos similares - e

30"If a conflict arises between two persons and they cannot resolve it themselves, then in all cultures and societies it is logical for those two persons to call upon a third to assist in its resolution... The triad contains a basic tension. To the extent that the triadic figure appears to intervene in favour of one of the two disputants and against the other, the perception of the situation will shift from the fairest to the most unfair of configurations: two against one. Therefore the principal characteristics of all triadic conflict resolvers will be determined by the need to avoid the perception of two against one, for only then can they rely on their basic social logic." (SHAPIRO e STONE SWEET, 2002, p. 211).

Revista de Direito, Estado e Telecomunicações, v. 1, n. 1, p. 181-202 (2009)

DOI: https://doi.org/10.26512/lstr.vli1.21743 
não formulada por exceção para esta ou aquela parte. Desse modo, busca-se a exclusão de influências meramente políticas na decisão, ao que, adotada a noção para entes reguladores, resulta na chamada judicialização da política. ${ }^{31}$ Isso significa, paradoxalmente, que a instância reguladora é uma instância de formulação política - mas busca-se, por garantias institucionais, assegurar que a política assim formulada não signifique a dominação de uma visão política sobre as demais. No caso do adversarial legalism, a composição colegiada, em imitação à estrutura dos tribunais, é um aspecto estrutural importante para a garantia de imparcialidade das decisões.

A meta-regulation, por sua vez, pressupõe que o resultado da avaliação da regulação siga uma racionalidade técnica, no mais das vezes sob o ponto de vista econômico. Também se exige que haja uma imunização da regulação frente à política, porém para que prevaleçam motivos técnicos para a aferição da necessidade ou desnecessidade da regulação. Essa imunização depende da garantia de que os mecanismos de influência política (representativa) não irão afetar as decisões do regulador. Parte-se, junto da Teoria da Regulação Econômica de Stigler ${ }^{32}$, da justificativa de as decisões políticas democráticas não representam de fato a escolha do público. Desse modo, fazer prevalecer a racionalidade técnica seria um modo de dar voz aos excluídos e sub-representados, que iriam se beneficiar do aumento geral de bem-estar social decorrente de políticas públicas responsáveis. Uma vez que a racionalidade técnica subjacente adotada pela doutrina e pela prática é, no mais das vezes, a racionalidade econômica, o resultado é a chamada economização da política. Se é necessário afastar ao máximo a interferência política nas decisões dos reguladores, a estrutura de

${ }^{31}$ Lembramos que a origem do adversarial legalism é a experiência jurídica norteamericana, que incorpora, por exemplo, a doutrina do precedente. Assim, cabe a ressalva de que a judicialização da política tem significado específico, que difere de uma acepção imediatamente relacionada à experiência de outros países que não os EUA.

${ }^{32}$ Parte-se, na Teoria da Regulação Econômica, do pressuposto de que o que se entende por escolha política democrática é na verdade o produto da influência de determinados grupos de interesse. Ao invés de refletir o interesse público, a regulação seria 0 produto de decisões que tendem a conceder benefícios concentrados a certos grupos e a distribuir os custos desses benefícios de forma difusa, pois a resistência de grupos difusos (sub-representados e não organizados) é menor do que a de grupos menores e coesos (Cf. STIGLER, 2004.). 
uma agência reguladora não pode estar vinculada hierarquicamente aos órgãos políticos tradicionais. Desse modo, como características estruturais essenciais, surgem a ausência de subordinação hierárquica e o mandato fixo dos funcionários de alto nível hierárquico. O mandato fixo é uma garantia da própria ausência de subordinação hierárquica. Aliada a essas características está a necessidade de autonomia financeira, para evitar o uso da prerrogativa orçamentária como forma de controle político. Por fim, em Estados em que há a noção de personalidade jurídica, como o Brasil, a presença de personalidade jurídica própria é mais um elemento estrutural de busca de maior independência, pois permite a assunção pelo próprio regulador de direitos e obrigações sem a necessidade de referendo - ou a possibilidade de veto - de estruturas hierárquicas superiores.

\section{Critério funcional}

No que diz respeito às funções exercidas pelos entes reguladores, estas serão determinadas, em primeiro lugar, pela concepção do papel do Estado frente ao mercado. Uma vez que se parte da busca de confiança no Estado por parte dos agentes econômicos, essas funções envolvem necessariamente a gestão dos aspectos fiduciários relacionados à atividade regulada.

Assim, em primeiro lugar, o ente regulador deve estabelecer os parâmetros comuns que determinam as relações no mercado. Para que os agentes econômicos invistam em determinado setor, é importante reduzir os riscos envolvidos na adoção de parâmetros industriais e nas condições de relacionamento com os outros agentes do mercado. Fixar parâmetros técnicos e diretrizes de relacionamento entre os agentes do mercado é, logo, responsabilidade do ente regulador. Esses parâmetros e essas diretrizes não se podem afastar das práticas do mercado, e devem seguir as tendências globais de cada setor. A ruptura com esta necessidade prática resulta em quebra da relação de confiança dos agentes privados e fuga de capital para outros Estados mais afinados com as necessidades do mercado. Desse modo, função característica dos entes reguladores é a normativa. Cabe às agências reguladoras normatizar os parâmetros técnicos e as condições de relacionamento entre os agentes do setor regulado.

Adicionalmente, especialmente em setores de infraestrutura - em que há um legado do uso do monopólio como meio de promoção do desenvolvimento -, compete à agência reguladora controlar o ingresso e a 
permanência de agentes no mercado regulado. Por vezes, a presença de barreiras à entrada de novos competidores é condição fiduciária para o ingresso de investimentos. Além disso, o reconhecimento pelo Estado de que um determinado agente pertence a um mercado regulado (mediante, por exemplo, a presença ou ausência da devida licença ou autorização), é condição para captação de investimentos por aquele agente. Isso significa, todavia, um objetivo paradoxal em um Estado reformado para estimular o market-led growth. Não é à toa que a remoção de barreiras regulatórias à entrada está na ordem do dia no que diz respeito ao programa atual de reforma do Estado.

Não obstante, essa função serve à finalidade de busca de poder econômico descrita inicialmente neste artigo. A existência de oligopólios regulamentados - sustentados por fortes barreiras regulatórias à entrada - é instrumento de barganha do Estado frente a grandes empresas transnacionais. Estas, de um lado, condicionam a continuidade de seus investimentos à permanência das barreiras a novos competidores. O Estado, por sua vez, usa a manutenção das barreiras como eventual sanção à descontinuidade de investimentos. E, por fim, o fato de os agentes econômicos necessitarem da anuência estatal para serem considerados integrantes de um mercado regulado e, em conseqüência, obter financiamentos junto à comunidade financeira internacional, serve de contraponto à perda de poder econômico do Estado. Mais do que a capacidade de uso da força para fechar determinada empresa, condicionamentos administrativos ao exercício de atividades reguladas são formas fiduciárias de controle e manutenção de investimentos privados uma vez que a reação dos financiadores do negócio à uma eventual retirada da anuência estatal (revogação de uma concessão, por exemplo), tornará absolutamente desnecessário o recurso ao poder político: uma empresa sem concessão estará fechada antes mesmo de o Estado agir, pois a mera perspectiva de fechamento já provocará a evasão de capitais dos investidores. Entretanto, como se verá adiante, a procedimentalização dessa função é requisito para a manutenção da confiança dos agentes de mercado, motivo pelo qual seu exercício se identifica com o modelo do adversarial legalism - por instituir barreira à competição, essa função é incompatível com o modelo de meta-regulation fundado em uma racionalidade econômica pró-competitiva. 
Em contraponto, a liberalização de setores regulados e o consequente aumento de interessados e regulados demanda o exercício pela agência reguladora de função de resolução de conflitos. Caso haja maior incidência do modelo de adversarial legalism, a tendência será de assunção pela agência reguladora de funções típicas do processo judicial - no caso das agências reguladoras norte-americanas, por exemplo, a Suprema Corte entende possível que elas se pronunciem de forma final sobre os chamados conflitos de direito público ${ }^{33}$, e exerçam função de dilação probatória (fact finding) nos demais conflitos. Caso prevaleça o modelo de meta-regulation, essa função encorajará o uso de mecanismos alternativos de resolução de disputas, privilegiando soluções negociadas ou consensuais, quando possível.

Por fim, como forma de preservação de sua autoridade, as agências reguladoras possuem a função de aplicação de sanções. $\mathrm{O}$ modelo de adversarial legalism, por estar vinculado à tradição norte-americana, tem por característica a adoção de sanções mais graves e onerosas do que aquelas tradicionalmente previstas em modelos de administração burocrática, por exemplo. ${ }^{34} \mathrm{O}$ uso da meta-regulation, contudo, é compatível com essa função, pois, como dito, a possibilidade de recurso a meios mais graves de resolução de conflitos é vista como incentivo à adoção de comportamentos econômicos mais racionais. Ademais, a eventual transferência de funções de resolução de conflitos a estruturas judicializadas pode ser mecanismo para a menor ingerência estatal sobre os setores regulados - conferindo-se aos agentes econômicos mais oportunidades de gerirem a si mesmos e apenas recorrerem ao Estado se frustrada essa autogestão.

\section{Critério procedimental}

No exercício de suas funções, as agências reguladoras seguem procedimentos distintos dos historicamente atribuídos à administração burocrática. No que concerne a aspectos em que prevaleça o adversarial legalism, a tendência será a adoção de procedimentos mais rígidos, pautados

${ }^{33}$ Conflitos de direito público são aqueles que envolvem a aplicação direta de algum programa regulatório.

${ }^{34}$ Cf. KAGAN, 2007, p. 102.

Revista de Direito, Estado e Telecomunicações, v. 1, n. 1, p. 181-202 (2009)

DOI: https://doi.org/10.26512/lstr.vli1.21743 
pela transparência das ações do órgão regulador e pela presença de minuciosa fundamentação legal nas atividades regulatórias. A fundamentação legal minuciosa, referenciada em direitos subjetivos claramente expressos pela lei, busca limitar a discricionariedade do regulador e possibilitar a revisão judicial dos atos do regulador que extrapolem os limites legais. ${ }^{35}$

Partindo-se da idéia da submissão estatal à busca de poder econômico, procedimentos pautados no adversarial legalism terão maior profusão no exercício de funções que possam afetar direitos de propriedade e liberdade dos agentes com maior poder econômico. Assim, infere-se que o adversarial legalism tenderá a prevalecer nos casos de controle do ingresso e permanência de agentes no mercado regulado e de aplicação de sanções. Nessas hipóteses, a confiança dos agentes regulados no Estado está diretamente relacionada à presença de limitada discricionariedade e à maior previsibilidade da atuação estatal.

A meta-regulation, a seu modo, pressupõe procedimentos mais flexíveis e voltados à obtenção da negociação e do consenso. Procedimentos dessa natureza tenderão a prevalecer no exercício da função normativa e na resolução de conflitos, hipóteses em que a confiança dos agentes regulados no Estado está relacionada à adequação das práticas governamentais ao mercado.

\section{Conclusão: a oportunidade de agregar novos objetivos à atuação reguladora}

A crise econômica do Estado e a busca por uma nova forma de atuação estatal trouxeram mecanismos institucionais que permitem a organização da função regulatória em maneiras as mais diversas. A deregulation, expressa no presente trabalho no binômio adversarial legalism e meta-regulation, na busca da implementação de uma nova relação entre Estado e mercado, trouxe à mesa novos mecanismos de atuação estatal, que se integram em maior ou menor grau nas experiências concretas de adoção das agências reguladoras.

${ }^{35}$ Cf. KAGAN, 2007, p. 103.

Revista de Direito, Estado e Telecomunicações, v. 1, n. 1, p. 181-202 (2009) 
Essa busca por meios mais eficazes de influenciar no poder econômico o toolkit de sobrevivência de Di Plínio -, na medida em que apresenta novas características e novos modos de pensar a atuação estatal, se revela uma oportunidade de agregar objetivos outros, que não o mero desenvolvimento econômico, à regulação. $\mathrm{O}$ fato de as agências reguladoras, em países como o Brasil, terem sido implementadas em um contexto de busca por capital para o financiamento do desenvolvimento econômico, não impede que novas racionalidades sejam incorporadas em seus processos de interação com o mercado. A desregulação, portanto, é uma oportunidade de repensar a atuação estatal também na promoção de uma pauta de direitos desvinculada do mero desenvolvimento econômico. Se o Estado conseguiu sobreviver à internacionalização do capital e à erosão da base de financiamento do Estado nacional por meio de mecanismos institucionais que se sustentam na cooperação - e não apenas na coerção -, o uso desses mecanismos pode se revelar uma ferramenta importante para dirigir o poder econômico a finalidades como a redução de desigualdades sociais, a promoção da dignidade humana ou a proteção a liberdades individuais.

\section{Bibliografia}

ANDERSON, Perry. Balanço do neoliberalismo. In: SADER, Emir; GENTILI, Pablo (Orgs.). Posneoliberalismo: as políticas sociais e o Estado democrático. Rio de Janeiro: Paz e Terra, 2000, p. 9-23. ARIÑO ORTIZ, Gaspar. Principios de derecho público económico. Granada: Comares, 2004.

AYRES, Ian e BRAITHWAITE, John. Responsive Regulation: Transcending the Deregulation Debate. New York : Oxford University Press, 1992.

BRAITHWAITE, John. Meta Regulation for Access to Justice. In: Presentation to General Aspects of Law (GALA) Seminar Series, University of California, Berkeley, 2003. Disponível em http://www.law.berkeley.edu/centers/kadish/gala03/Braithwaite $\% 20 K e n t . p d f$. Consultado em 08/07/2007.

CASTELLS, Manuel. O poder da identidade. A era da informação: economia, sociedade e cultura, v. 2. $5^{\text {a }}$ ed. São Paulo: Paz e Terra, 2006. 
DI PLINIO, Giampiero. Il common core della deregulation: dallo Stato regolatore alla Costituzione economica sovranazionale. Milano: Giuffrè, 2005.

JACOBS, Scott H. The Second Generation of Regulatory Reforms. IMF Conference on Second Generation Reforms, 8-9 November 1999. Disponível em http://www.imf.org/external/pubs/ft/seminar/reforms/index.htm. Consultado em 08/07/2007.

JUSTEN FILHO, Marçal. O direito das agências reguladoras independentes. São Paulo: Dialética, 2002.

GIDDENS, Anthony (org.). O debate global sobre a terceira via. São Paulo: Editora UNESP, 2007.

HANCHER, Leigh e MORAN, Michael. Organizing Regulatory Space. In: HANCHER, Leigh e MORAN, Michael (orgs.). Capitalism, Culture and Economic Regulation. Oxford : Oxford University Press, 1989, p. 271300.

HUBER, Peter W.; KELlOGG, Michael K.; THORNE, John. Federal Telecommunications Law. $2^{\mathrm{a}}$ ed., New York: Aspen Law \& Business, 1999.

KAGAN, Robert. Globalization and legal change: The "Americanization", of European law? In: Regulation \& Governance, n. 1, jun. 2007, p. 99120.

Disponível

em http://www.blackwellpublishing.com/journal.asp?ref=1748-5983\&site=1. Consultado em 05/07/2007. ${ }^{36}$

MARQUES NETO, Floriano de Azevedo. Agências reguladoras independentes: fundamentos e seu regime jurídico. Belo Horizonte : Fórum, 2005.

MORGAN, Bronwen. The Economisation of Politics: Meta-regulation as a form of Nonjudicial Legality. In: Social and Legal Studies, Vol. 12, n. 4, p. 489-523, December 2003. Disponível em http://papers.ssrn.com/sol3/papers.cfm?abstract_id=542882\#

PaperDownload. Consultado em 01/07/2007. 
MORGAN, Bronwen e YEUNG, Karen. An Introduction to Law and Regulation - Text and Materials. Cambridge: Cambridge University Press, 2007.

PELTZMAN, S. A Teoria Econômica da Regulação depois de uma década de desregulação. In: MATTOS, Paulo (org.). Regulação Econômica e Democracia: o debate norte-americano. São Paulo: Ed. 34, 2004, p. 81130.

PEREIRA, Luiz Carlos Bresser. Gestão do setor público: estratégia e estrutura para um novo Estado. In: PEREIRA, Luiz Carlos Bresser e SPINK, Peter Kevin (orgs.). Reforma do Estado e administração pública gerencial. $2^{a}$ ed. Rio de Janeiro: Fundação Getúlio Vargas, 1998, p. 21-39.

SHAPIRO, Martin e STONE SWEET, Alec. On Law, Politics and Judicialization. Oxford: Oxford University Press, 2002, p. 211 Apud: MORGAN, Branwen. The Economisation of Politics: Meta-regulation as a form of Nonjudicial Legality. Social and Legal Studies, Vol. 12, n. 4, p. 489-523, December 2003, p. 7. Disponível em http://papers.ssrn.com/sol3/papers.cfm?abstract_id=542882\#PaperDownlo ad. Consultado em 01/07/2007.

STIGLER, George J. Teoria da Regulação Econômica. In: MATTOS, Paulo (org.). Regulação Econômica e Democracia: o debate norte-americano. São Paulo: Ed. 34, 2004, p. 13-49. 